\title{
Fracture Resistance of Retreated Roots Using Different Retreatment Systems
}

\author{
Kursat Era \\ Tamer Tasdemir ${ }^{b}$ \\ Seyda Herguner Sisoc \\ Davut Celik ${ }^{\mathrm{b}}$ \\ Sabri Cora ${ }^{b}$
}

\section{ABSTRACT}

Objectives: This study was designed to evaluate the fracture resistance of retreated roots using different rotary retreatment systems.

Methods: Forty eight freshly extracted human canine teeth with single straight root canals were instrumented sequentially increasing from size 30 to a size 55 using K-files whit a stepback technique. The teeth were randomly divided into three experimental and one control groups of 12 specimens each. The root canals were filled using cold lateral compaction of gutta-percha and AH Plus (Dentsply Detrey, Konstanz, Germany) sealer in experimental groups. Removal of gutta-percha was performed with the following devices and techniques: ProTaper Universal (Dentsply Maillefer, Ballaigues, Switzerland), R-Endo (Micro-Mega, Besançon, France), and Mtwo (Sweden \& Martina, Padova, Italyl rotary retreatment systems. Control group specimens were only instrumented, not filled or retreated. The specimens were then mounted in copper rings, were filled with a self-curing polymethylmethacrylate resin, and the force required to cause vertical root fracture was measured using a universal testing device. The force of fracture of the roots was recorded and the results in the various groups were compared. Statistical analysis was accomplished by one-way ANOVA and a post hoc Tukey tests.

Results: There were statistically significant differences between the control and experimental groups $(\mathrm{P}<$.05). However, there were no significant differences among the experimental groups.

Conclusions: Based on the results, all rotary retreatment techniques used in this in vitro study produced similar root weakness. (Eur J Dent 2011;5:387-392)

Key words: Fracture resistance; Retreatment; Root fracture; Rotary instruments.

a Akdeniz University, Faculty of Dentistry, Department of Endodontics, Antalya, Turkey.

b Karadeniz Technical University, Faculty of Dentistry, Department of Endodontics, Trabzon, Turkey.

Cumhuriyet University, Faculty of Dentistry, Department of Restorative Dentistry, Sivas, Turkey.

- Corresponding author: Kursat Er

Akdeniz Universitesi, Dis Hekimligi Fakultesi,

Endodonti Anabilim Dali, Antalya, Turkey.

Phone: +90 2423106965

Fax: +902423106967

E-mail: kursaterdakdeniz.edu.tr

\section{INTRODUCTION}

Residual necrotic tissue or bacteria beneath either gutta-percha or sealer can be responsible for periapical inflammation or pain. ${ }^{1}$ Thus, the main objective of nonsurgical retreatment is to remove all material filling from the root canal and to regain access to the apical foramen. ${ }^{2}$ The techniques used to remove gutta-percha are varied and included the use of hand or rotary instruments, with or without heat, and solvents and/or ultrasound. . $^{3,4}$ 
Various nickel-titanium (NiTi) rotary endodontic instruments have been developed to facilitate cleaning and shaping of root canals. To improve safety preparation and to prepare more appropriate shapes, new instrument designs with noncutting tips, radial lands, varying tapers and rake angles, and changing pitch lengths have been developed. ${ }^{5}$ Rotary NiTi instruments have also been proposed to remove filling materials from root canal walls, and various studies reported their efficacy, cleaning ability, and safety. 4,6,7 Recently, three new NiTi retreatment instruments have been introduced commercially: the ProTaper Universal (Dentsply Maillefer, Ballaigues, Switzerland), Mtwo (Sweden \& Martina, Padova, Italy) and the R-Endo (Micro-Mega, Besançon, France) systems.

Endodontic and restorative procedures have been suggested to be precipitating factors for tooth fractures. 8,9 Minimal tooth cutting in such procedures is the most effective measure for preventing root fractures in root-filled teeth. ${ }^{10}$ Cavity preparation, ${ }^{11}$ root canal instrumentation, ${ }^{8,12}$ filling strains ${ }^{13-15}$ and post placement ${ }^{16,17}$ have been investigated as major causes of fracture. To date, the re-instrumentation efficacy on the fracture resistance of roots after retreatment has not been investigated in the literature. For this reason, the aim of the present study was to investigate the fracture resistance of retreated roots with three rotary NiTi systems (ProTaper Universal, R-Endo, and Mtwol, in the retreatment of gutta-percha root fillings.

\section{MATERIALS AND METHODS}

Forty-eight human mature canines, extracted for periodontal reasons, were used in this in vitro study. Human teeth were consisted of teeth from patients 18 to 35 years of age. The teeth were free of caries, any previous restorations, and preexisting fractures or cracks when surveyed under transillumination. Preoperative mesio-distal and bucco-lingual radiographs were taken for determining root canal morphology and the teeth were evenly distributed in terms of both round and oval shaped canals into the test groups. The teeth had determined radiogarphically as having calcified canals and canals with large apical foramina were excluded. Selected teeth with similar dimensions were cleaned of debris and soft tissue remnants and were stored in physiological saline solution at $4^{\circ} \mathrm{C}$ until required. The teeth were sectioned at the cemento-enamel junction using high-speed diamonds (Dentsply Maillefer) and water spray. To standardize the root canal lengths, the roots were shortened to a uniform length of $16 \mathrm{~mm}$. A size 10 K-file (Dentsply Maillefer) was placed into the canal until being visible at the apical foramen. The working length was determined by subtracting 1 $\mathrm{mm}$ from this measurement. Root canal preparation was performed with K-files using a stepback technique. Instrumentation was standardized with a size $30 \mathrm{~K}$-file reaching full working length, a size 55 file $5 \mathrm{~mm}$ coronally and a final coronal flaring with Gates Glidden drills (size: 2 and 3; Dentsply Maillefer). A size $10 \mathrm{~K}$-file was used during the root canal preparation to maintain patency of the canal. At each change of instrument, $2 \mathrm{~mL}$ of $2.5 \% \mathrm{NaOCl}$ was used. When the instrumentation of root canals was completed, $17 \%$ EDTA was applied for $1 \mathrm{~min}$ for smear layer removal and the canals flushed again with $10 \mathrm{~mL} 2.5 \% \mathrm{NaOCl}$. The root canals were then dried with paper points. Thirty-six teeth were filled with laterally compacted gutta-percha (Diadent, Seoul, Korea) and AH Plus (Dentsply Detrey, Konstanz, Germanyl sealer that was mixed according to the manufacturer's instruction. Teeth were radiographed in buccolingual and mesiodistal directions to confirm the adequacy of the root canal obturation. The remaining twelve teeth were not filled and served as control. The access openings were sealed with a temporary filling material (Cavit G, 3M Espe, Seefeld, Germany) and the teeth were stored at $37^{\circ} \mathrm{C}$ in $100 \%$ humidity for 2 weeks.

All samples were randomly divided into three experimental and one control groups with 12 specimens each. Temporary filling materials were removed from access openings. Before starting the experimental phase, a drop of $0.5 \mathrm{~mL}$ chloroform solvent was introduced in each canal to soften the gutta-percha. Two or three additional drops of solvent were applied as required to reach the working length. During the retreatment, root canals were constantly irrigated with $2.5 \% \mathrm{NaOCl}$.

\section{Group 1 (ProTaper Universal Group)}

ProTaper Universal instruments were used in a handpiece with adjustable torque (NiTi Anthogyr Control, Dentsply Maillefer) according to the manufacturer's instructions. In brief, D1 19\% taper, size 30), D2 (8\% taper, size 25$)$ and D3 (7\% taper, size 20) were sequentially used in a crowndown manner to reach the preestablished working length; they were manipulated in a brushing action. The rotational speed was set at $500 \mathrm{rpm}$ as recommended. Root canal refinement was accomplished with ProTaper Universal rotary shaping [S1 (shaping file no.1; taper 2-11\%; size 17) 
and S2 (shaping file no.2; taper $4-11.5 \%$; size 20 )] and finishing [F1 (finishing file no.1; taper 5.5-7\%; size 20 ), F2 (finishing file no.2; taper $5.5-8 \%$; size 25 ) and F3 (finishing file no.3; taper 5-9\%; size 30)] instruments, which were used in a gentle brushing action at a speed of $300 \mathrm{rpm}$ according to the manufacturers' instruction.

\section{Group 2 (R-Endo Group)}

R-Endo retreatment files were used with a rotary electric motor and handpiece (Inget ${ }^{\circledR} 06$ Contra-Angle, Micro-Megal at 300 rpm. A K-file ( $2 \%$ taper, size 25 ) was used with $1 / 4$ turn pressure directed towards the apex to create a pathway thus allowing the centering and the alignment of the next instrument. Re instrument $112 \%$ taper, size 25) was used 1 to $3 \mathrm{~mm}$ beyond the pulp chamber floor with circumferential filing. R1 rotary instrument ( $8 \%$ taper, size 25 ) was used to penetrate from the coronal third to the beginning of the middle third through repeated apically directed pushing actions. R2 rotary instrument $16 \%$ taper, size 25) was used from the middle third to the beginning of the apical third. R3 rotary instrument $14 \%$ taper, size 25) was used at the working length with circumferential filing action. Finally, the retreatment procedure was concluded with the use of RS rotary instrument ( $4 \%$ taper, size 30 ) at the working length.

\section{Group 3 (Mtwo Group)}

Mtwo instruments were used with the air-driven torque-limited rotation handpiece (Mtwo Direct VDW, München, Germanyl at 300 rpm. Torque settings were selected with a turning ring chosen for each file according to the manufacturer's instructions. The root canal filling material gradually was removed by Mtwo R2 (5\% taper, size 25) and Mtwo R1 (5\% taper, size 15) instruments, respectively, until slight resistance was encountered. These two instruments were used with circumferential filing movements and without downward pressure. A Cpilot file (VDW) size 10 was used to negotiate the root canal to full working length. After the working length was reached, conventional Mtwo rotary instruments were used to remove the filling material in a circumferential filing motion while pressing against the root canal walls: Mtwo 4\% taper, size 10; Mtwo 5\% taper, size 15; Mtwo 6\% taper, size 20; Mtwo 6\% taper, size 25 and Mtwo 5\% taper, size 30 .

Group 4 (Control Group)

Roots were only instrumented, not filled or retreated.
All instruments were used in two root canals and were then discarded. Also deformed instruments were discarded. Gutta-percha removal was judged to have been completed when the working length was reached and no more gutta-percha could be removed with the instruments used. Radiographs were taken to confirm complete removal of gutta-percha.

The roots were coated with an air thinned 0.3 $\mathrm{mm}$ layer of polyvinylsiloxane (President light body, Coltene-Whaledent AG, Altstatten, Switzerland) to simulate a periodontal ligament. Copper rings 10 $\mathrm{mm}$ diameter and $25 \mathrm{~mm}$ in height were obtained using cylindrical moulds. A selfcuring polymethylmethacrylate resin (Vertex; Dentimex Dental, Zeist, The Netherlands) was used in the preparation of the cylinders. Five millimeters of the roots were embedded in the acrylic cylinders exposing $11 \mathrm{~mm}$. The copper rings with the teeth were then placed into a Universal Testing Machine IInstron, Canton, MA, USAl and a compressive loading was applied vertically to the coronal surfaces of roots with loading rate of $1 \mathrm{~mm} \mathrm{~min}{ }^{-1}$ until fracture occurred. The load at which failure occurred was recorded and expressed in Newtons.

The data were analysed statistically using oneway analysis of variance (ANOVA) and Tukey post

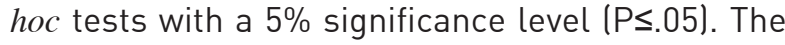
statistical tests were performed using the SPSS (Version 10.0; SPSS Inc., Chicago, IL, USA).

\section{RESULTS}

The minimum, maximum and mean fracture resistance $(\mathrm{N})$ and standard deviation for each of the groups are presented in Table 1. The mean force of fracture values was $111.7 \mathrm{~N}, 133.25 \mathrm{~N}, 164.45 \mathrm{~N}$, and $334.18 \mathrm{~N}$ for groups $1-3$ and the control group, respectively. There was a significant difference between the experimental groups and the control group $(P<.05)$. However, no significant differences were found among the three experimental groups (P>.05).

\section{DISCUSSION}

The success of endodontics is related to the appropriate execution of the different treatment phases. During root canal instrumentation, the removal of dentine is necessary to promote cleaning and disinfection, as well as to prepare the root canal system to receive the filling material. ${ }^{12}$ It is generally accepted that this unavoidable loss of dentine may weaken the root and create an increased risk of fracture. ${ }^{9}$ For this reason, there is a 
general trend to restore the roots with a reinforcing material. ${ }^{9-11,13,15}$

Current endodontic rotary instruments have increasing and variable tapers. Thus, the tapers of root canals are increased. This increase by removing more dentine from the canal wall diminishes the structural integrity of the root. ${ }^{18}$ Using finiteelement analysis, Ricks-Williamson et $\mathrm{al}^{19}$ found the magnitude of generated radicular stresses to be directly correlated with the simulated canal diameters. Wilcox et $\mathrm{a}^{20}$ found that root surface craze lines formed on roots where greater percentages of the canal wall were removed. Zandbiglari et al ${ }^{12}$ demonstrated that fracture resistance of instrumented roots is significantly lower when canals are prepared with instruments with an increasing taper. As a consequence, the authors recommended that excessive coronal enlargement of the root canal must be avoided to prevent unnecessary weakening of the root. Sathorn et $\mathrm{al}^{21}$ showed that the dentine thickness was not the only determining factor. Curvature of the external proximal root surface, canal size, and shape all interact to influence susceptibility and the pattern of fracture as well. Conversely, it has been reported 22 that no significant correlation exists between fracture load and size of the root, size of the prepared canal, width of the canal walls after instrumentation, and taper of the root or of the canal.

The major factors associated with endodontic failure are the persistence of microbial infection in the root canal system and/or the periradicular area. ${ }^{1}$ Thus, root canal retreatment has largely replaced periradicular surgery for the management of persisting or emerging disease. Therefore, it is important to remove as much sealer and guttapercha as possible during retreatment, to uncover remnants of necrotic tissue or bacteria that might set as the antigenic source. ${ }^{7}$

Conventionally, the removal of gutta-percha using hand files with or without solvent can be a tedious, time-consuming process, especially when the root filling material is well condensed. ${ }^{23}$ Thus, the use of rotary NiTi instruments in root canal retreatment may decrease patient and opera- tor fatigue. Various rotary systems have been used to remove the filling material during endodontic retreatment. Recently, new instruments produced for retreatment purposes were added to conventional rotary instruments for canal preparation (ProTaper Universal, R-Endo, and Mtwo retreatment instruments). These instruments each have a cutting tip to allow the instrument to progress easily in the filling material, and they might lead the way to other instruments that will be used in the future. ${ }^{24}$

To date, the re-instrumentation efficacy on the fracture resistance of roots after retreatment has not been investigated in the literature. For this reason, the aim of the present study was to investigate the fracture resistance of retreated roots with three rotary NiTi systems (ProTaper Universal, R-Endo, and Mtwol, in the retreatment of gutta-percha root fillings. According to the present study, there was no statistically significant difference among the retreated groups. The fracture resistances in each of the experimental groups were significantly decreased compared to the instrumented, but not filled or retreated, group (control group). Root canal filling material is removed during re-instrumentation. But, at the same time, an amount of extra dentine is removed from the root structure. This may explain the difference between the experimental and control groups in this study. Additionally, during reinstrumentation, the coronal taper increases and the coronal third of root stresses tend to increase for masticatory loading.

Previous studies have reported that the filling residue traced in the canal would be minimized when the enlargement in the retreatment was bigger than the enlargement performed before the canal filling. ${ }^{25,26}$ Therefore, authors have recommended that the retreatment procedure would be completed with the instrument used in enlargement, increased by only one size, before the filling. ${ }^{4,24}$ However, in this study, the final instrument used in retreated groups were the same size as those in the control group for similar canal dimensions.

Table 1. Minimum, maximum and mean fracture resistance (N) and the standard deviation (SD) for each of the groups.

\begin{tabular}{lcccc}
\hline Groups & $\mathrm{n}$ & Mean (SD) & Minimum & Maximum \\
\hline ProTaper Universal & 12 & $111.70(35.39)^{\mathrm{a}}$ & 66.68 & 197.10 \\
R-Endo & 12 & $133.25(19.94)^{\mathrm{a}}$ & 104.92 & 174.55 \\
Mtwo & 12 & $164.45(46.59)^{\mathrm{a}}$ & 100.02 & 233.38 \\
Control & 12 & $334.18(50.67)^{\mathrm{b}}$ & 262.80 & 465.78 \\
\hline
\end{tabular}

The same superscript letters indicate statistically no significant values $(P>05)$. 
Root canal instrumentation techniques can be weakening the tooth structures. This weakening may be tolerated with root canal filling materials. To date, numerous root canal filling materials have been proposed to reinforce teeth through root canal treatments using different fillings. 13,27,28 However, it is still controversial as to whether or not these fillings increase the strength of root dentin. For this reason, it appears necessary to develop new instruments, methodologies, and filling materials to minimize the fracture resistance of teeth in retreatment procedures.

\section{CONCLUSIONS}

Under the conditions of this in vitro study, all rotary retreatment techniques produced similar root weakness.

\section{REFERENCES}

1. Nair PN. Pathogenesis of apical periodontitis and the causes of endodontic failures. Crit Rev Oral Biol Med 2004;15:348-381.

2. Stabholz A, Friedman S. Endodontic retreatment case selection and technique. Part-2: treatment planning for retreatment. J Endod 1988;14:607-614.

3. Barletta FB, de Sousa Reis M, Wagner M, Borges JC, Dall'Agnol C. Computed tomography assessment of three techniques for removal of filling material. Aust Endod J 2008;34:101-105.

4. Tassdemir T, Er K, Yildirim T, Celik D. Efficacy of three rotary NiTi instruments in removing gutta-percha from root canals. Int Endod J 2008;41:191-196.

5. Young GR, Parashos P, Messer HH. The principles of techniques for cleaning root canals. Aust Dent J 2007;52:S52-63.

6. Zmener $\mathrm{O}$, Pameijer $\mathrm{CH}$, Banegas $\mathrm{G}$. Retreatment efficacy of hand versus automated instrumentation in oval-shaped root canals: an ex vivo study. Int Endod J 2006;39:521-526.

7. Saad AY, Al-Hadlaq SM, Al-Katheeri NH. Efficacy of two rotary NiTi instruments in the removal of gutta-percha during root canal retreatment. J Endod 2000;33:38-41.

8. Lam PPS, Palamara JEA, Messer HH. Fracture strength of tooth roots following canal preparation by hand and rotary instrumentation. J Endod 2005;31:529-532.

9. Siso $S H$, Hürmüzlü $F$, Turgut M, Altundasar $E$, Serper A, Er K. Fracture resistance of the buccal cusps of root filled maxillary premolar teeth restored with various techniques. Int Endod J 2007;40:161-168.

10. Reeh ES, Messer HH, Douglas WH. Reduction in tooth stiffness as a result of endodontic and restorative procedures. J Endod 1989;15:512-516.
11. Hurmuzlu F, Serper A, Siso SH, Er K. In vitro fracture resistance of root filled teeth using new-generation dentine bonding adhesives. Int Endod J 2003;36:770-773.

12. Zandbiglari T, Davids $H$, Schafer E. Influence of instrument taper on the resistance to fracture of endodontically treated roots. Oral Surg Oral Med Oral Pathol Oral Radiol Endod 2006;101:126-131.

13. Sagsen B, Er O, Kahraman Y, Akdogan G. Resistance to fracture of roots filled with three different techniques. Int Endod J 2007;40:31-35.

14. Pișkin B, Aydın B, Sarıkanat M. The effect of spreader size on fracture resistance of maxillary incisor roots. Int Endod J 2008;41:54-59.

15. Karapinar Kazandag M, Sunay H, Tanalp J, Bayirli G. Fracture resistance of roots using different canal filling systems. Int Endod J 2009;42:705-710.

16. Adanir N, Belli S. Evaluation of different post lengths' effect on fracture resistance of a glass fiber post system. Eur J Dent 2008;2:23-28.

17. Kıvanç BH, Alaçam T, Ulusoy ÖIA, Genç Ö, Görgül G. Fracture resistance of thin-walled roots restored with different post systems. Int Endod J 2009;42:997-1003.

18. Pilo R, Corcino G, Tamse A. Residual dentin thickness in mandibular premolars prepared with hand and rotary instruments. J Endod 1998;24:401-404.

19. Ricks-Williamson LJ, Fotos PG, Goel VK, Spivey JD, Rivera EM, Khera SC. A three-dimensional finite-element stress analysis of an endodontically prepared maxillary incisor. $J$ Endod 1995;21:362-367.

20. Wilcox LR, Roskelley C, Sutton T. The relationship of root canal enlargement to finger-spreader induced vertical root fracture. J Endod 1997;23:533-534.

21. Sathorn C, Palamara JEA, Palamara D, Messer HH. Effect of root canal size and external root surface morphology on fracture susceptibility and pattern: a finite element analysis. J Endod 2005;31:288-292.

22. Pitts DL, Matheny JE, Nicholls JI. An in vitro study of spreader loads required to cause vertical root fracture during lateral condensation. J Endod 1983;9:544-550.

23. de Oliveira DP, Barbizam JV, Trope M, Teixeira FB. Comparison between gutta-percha and resilon removal using two different techniques in endodontic retreatment. $J E n$ dod 2006;32:362-364.

24. Taşdemir T, Yildirim T, Celik D. Comparative study of removal of current endodontic fillings. J Endod 2008:34:326329.

25. Friedman S, Moshonov J, Trope M. Residue of gutta percha and a glass ionomer cement sealer following root canal retreatment. Int Endod J 1993;26:169 -172. 
26. Hassanloo A, Watson P, Finer Y, Friedman S. Retreatment efficacy of the epiphany soft resin obturation system. Int Endod J 2007;40:633-643.

27. Hammad M, Qualtrough A, Silikas N. Effect of new obturating materials on vertical root fracture resistance of endodontically treated teeth. J Endod 2007;33:732-736.

28. Ulusoy OI, Genc, O, Arslan S, Alacam T, Gorgul G. Fracture resistance of roots obturated with three different materials. Oral Surg Oral Med Oral Pathol Oral Radiol Endod 2007;104:705-708. 